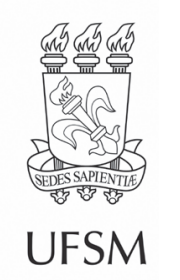

\title{
Artigos
}

\section{Intervalo hídrico ótimo e valores críticos de densidade como indicadores de recuperação de um solo sob sistemas florestais e pasto}

\section{Least limiting water range and critical bulk density values as recovery indicators of a soil under forest and pasture systems}

\author{
Lucas Luís Faustino' ${ }^{\oplus}$ \\ Cláudio Roberto Marciano" $\odot$
}

'Instituto Federal de Educação, Ciência e Tecnologia Goiano, Morrinhos, GO, Brasil "Universidade Estadual do Norte Fluminense Darcy Ribeiro, Campos dos Goytacazes, RJ, Brasil

\section{RESUMO}

O intervalo hídrico ótimo (IHO) é um indicador de qualidade física do solo para o crescimento de plantas determinado não só pela disponibilidade de água, mas também pela aeração e resistência que o solo oferece à penetração das raízes. O objetivo do trabalho foi avaliar a eficiência da revegetação com as leguminosas arbóreas Acácia, Sábia e Ingá, para a recuperação da qualidade física de um Argissolo Vermelho-Amarelo inicialmente sob pastagem degradada, utilizando como indicador o intervalo hídrico ótimo e as densidades críticas dele decorrentes. A área, localizada em Conceição de Macabú, Rio de Janeiro, constitui-se de cinco coberturas vegetais. Dessas, três foram plantios puros das leguminosas arbóreas acácia, sábia, e ingá, implantadas em 1998, em parcelas de 1500 m². As outras áreas, utilizadas como referência e adjacentes aos plantios de leguminosas, foram uma pastagem degradada e um fragmento florestal de Mata Atlântica. Amostras de solo, coletadas em anéis volumétricos nas camadas 0-0,10 e 0,10-0,20 m de profundidade, foram utilizadas para a obtenção da curva de retenção de água, da curva de resistência à penetração e do IHO em função da densidade. Em nenhuma área ou camada foram verificadas restrições à aeração do solo. Por outro lado, valores de resistência à penetração superiores ao limite crítico de 3,0 MPa foram verificados em grande parte dos casos, fazendo com que o IHO fosse menor que a água disponível. As densidades do solo críticas às plantas quanto a restrições mecânicas e hídricas ( $\mathrm{DSC}_{\mathrm{RP}}$ e Dsc ${ }_{\mathrm{IHO}}$ ) foram mais altas sob capoeira. As áreas sob leguminosas arbóreas apresentaram elevadas densidades médias e baixos valores de densidades críticas Dsc $_{\mathrm{RP}}$ e $\mathrm{DsC}_{\mathrm{IHO}^{\prime}}$ similares às da área sob pastagem. Pode-se concluir que o solo sob capoeira apresenta resiliência frente ao processo de compactação, e que após 17 anos da revegetação com leguminosas arbóreas não houve evidências consistentes de recuperação estrutural do solo.

Palavras-chave: Revegetação; Recuperação de áreas degradadas; Compactação do solo; Resistência à penetração 


\section{ABSTRACT}

The Least Limiting Water Range (LLWR) is an indicator of soil physical quality for plant growth determined not only by the availability of water, but also by aeration and soil resistance to root penetration. The objective of this work was to evaluate the LLWR and the critical values of bulk density of a Typic Hapludult soil under the Atlantic Forest, degraded pasture and revegetation with tree legumes. The area, located in Conceição de Macabu, RJ state, is constituted of five vegetation coverages. Of these, three were pure plantations of the Acacia auriculiformis, Mimosa caesalpiniifolia e Inga edulis tree legumes, implanted in 1998 in plots of $1.500 \mathrm{~m}^{2}$. The others, used as reference and adjacent to the legume plantations, were a degraded pasture and a forest fragment of Atlantic Forest. Soil samples, collected in volumetric rings in the 0-0.10 and 0.10-0.20 m depth layers, were used to obtain the water retention curve, penetration resistance curve and LLWR as a function of density. In no area or layer has been verified restrictions to soil aeration. On the other hand, RP values above the critical limit of 3.0 MPa were verified in most cases, making the LLWR smaller than the field capacity. Critical soil densities to plants for mechanical and water restrictions ( $\mathrm{DSC}_{\mathrm{RP}}$ and $\mathrm{DSC}_{\mathrm{IHO}}$ ) were higher under capoeira. The areas under leguminous trees, showing high average densities and low values of critical densities $\mathrm{Dsc}_{\mathrm{RP}}$ and $\mathrm{Dsc}_{\mathrm{HO}^{\prime}}$ similar to those of the area under pasture. It can be concluded that the soil under capoeira shows resilience to the compaction process, and that after 17 years of revegetation with leguminous trees there was no consistent evidence of structural soil.

Keywords: Revegetation; Recovery of degraded areas; Soil compaction; Soil resistance to penetration

\section{INTRODUÇÃO}

Os solos da região Norte Fluminense foram muito exauridos pela exploração agropecuária, o que pode ser evidenciado pela grande degradação física e perda da fertilidade em comparação com solos de áreas sob vegetação nativa. Isso ocorreu principalmente devido ao cultivo de cana-de-açúcar com o uso de queimadas, ao cultivo do café em encostas íngremes e à pecuária com pastagens mal manejadas (GAMA-RODRIGUES et al., 2008; GOMES; MARCIANO; FAUSTINO, 2018), resultado de um modelo de produção agropecuária intensivo-extrativista. A perda da qualidade física do solo é um processo gradual que se inicia com a deterioração da estrutura e termina com a perda diferencial de partículas por meio da erosão, sendo agravada pelo processo de compactação (REICHERT; SUZUKI; REINERT, 2007; SILVA et al., 2010).

A compactação do solo decorre da aplicação de cargas externas (pisoteio, tráfego de máquinas, ação mecânica de implementos, etc.) que levam à aproximação 
entre partículas e consequente aumento da densidade do solo (Ds) (SILVA et al., 2010). A redução do volume do solo se dá pela redução de seu espaço poroso (REICHERT; SUZUKI; REINERT, 2007), que ocorre pela conversão de poros de maior diâmetro em poros de diâmetro cada vez menor. Assim, até certo ponto do processo de compactação, o aumento da Ds vem acompanhado da redução na porosidade total (PT) e macroporosidade e do aumento na microporosidade (REICHERT; SUZUKI; REINERT, 2007; DIAS et al., 2016). Para solos originalmente com baixa macroporosidade, o aumento da Ds pela compactação poderá se dar até mesmo em decorrência da redução da nominal da microporosidade, como no caso do solo de textura francosiltosa sob cultivo convencional estudado em Silva, Kay e Perfect (1994).

Muitas vezes, a regeneração natural da cobertura vegetal em uma área degradada é lenta e incerta, devido à competição com as gramíneas e às queimadas rotineiras que dificultam o estabelecimento das plantas e reduzem o vigor do banco de sementes. Uma forma de reverter o cenário típico de áreas degradadas é a implantação de sistemas florestais com espécies leguminosas arbóreas, que são plantas de crescimento rápido, capazes de fazer a fixação de nitrogênio atmosférico em associação com as bactérias diazotróficas e de promover a ciclagem de nutrientes, possibilitando assim a recuperação produtiva desses solos (GAMA-RODRIGUES et al., 2008; MANHÃES et al., 2013).

Franco et al. (1992) relatam que, além de restabelecer a fertilidade de áreas de produção, as leguminosas, devido ao seu crescimento inicial rápido, têm permitido acelerar a sucessão secundária progressiva e pular as etapas iniciais da sucessão natural. A revegetação permite também a recuperação física dos solos, tanto pela ação direta das raízes (rompimento de camadas compactadas, retenção de partículas, estruturação do solo, etc.) como por efeitos indiretos decorrentes da recuperação química do solo e do incremento da atividade biológica. A baixa qualidade inicial de uma área degradada pode restringir o crescimento vegetativo das espécies usadas para a revegetação (KAISER et al., 2009), mas a própria atuação das plantas, principalmente as leguminosas, pode alterar rapidamente esse cenário. 
Em relação à qualidade física do solo, no clássico trabalho de revisão bibliográfica de Letey (1985) concluiu-se que o crescimento de plantas é afetado diretamente por quatro fatores: (i) disponibilidade de água; (ii) aeração; (iii) temperatura; e (iv) resistência mecânica à penetração das raízes. A degradação de um solo, em particular aquela decorrente da compactação, tem implicações negativas sobre esses fatores físicos, levando à redução da taxa de difusão de oxigênio e/ou ao aumento da resistência à penetração para níveis limitantes ao crescimento radicular, mesmo com o solo na faixa de umidade em que a água é considerara disponível às plantas.

Reichert, Suzuki e Reinert (2007) relatam que atributos físicos dos solos são facilmente alterados pelo uso e manejo, que essas alterações são de duração relativamente longa e difíceis de recuperar, e que essas divergências em relação às condições naturais têm efeitos significativos e negativos na produtividade. Em áreas sob uso agrícola contínuo, a descompactação do solo usualmente é feita por meio de operações mecanizadas que empregam grande esforço de máquina e mesmo financeiro. Esse esforço, no entanto, pode ter efeito efêmero, restrito a um único ciclo agrícola (SEKI et al., 2015), com a recuperação sendo revertida em pouco tempo pela continuidade do uso e manejo causadores da degradação. No limite, quando a degradação química e física do solo torna-se de difícil recuperação, essas áreas passam a ser destinadas a usos marginais, papel muitas vezes assumido pela pecuária de baixo nível tecnológico, conforme admitido inclusive no "Sistema de Avaliação da Aptidão Agrícola das Terras" (RAMALHO FILHO; BEEK, 1995). Por outro lado, quando se objetiva a interrupção do uso agropecuário de uma área degradada e sua reincorporação à paisagem natural, pode-se optar por não fazer nenhum grande esforço inicial para acelerar sua recuperação e deixar que isso ocorra de modo mais natural, com a qualidade física, química e biológica sendo melhorada gradativamente como consequência da revegetação (FRANCO et al., 1992; OLIVEIRA et al., 2019).

Para que a efetividade da recuperação de uma área degradada seja adequadamente avaliada, é importante que os vários aspectos determinantes da 
qualidade do solo sejam considerados. Para isso, pode-se utilizar um conjunto de variáveis indicadoras ou, então, algum índice ou variável que represente esses diversos aspectos de forma integrada (SILVA et al., 2010). Nesse contexto, o intervalo hídrico ótimo (IHO) destaca-se por representar a faixa de água no solo em que vários aspectos determinantes do desenvolvimento de plantas (disponibilidade de água, aeração e resistência do solo à penetração) encontram-se dentro de limites considerados adequados (LETEY, 1985). Desde sua introdução no Brasil por Tormena, Silva e Libardi (1998), a partir do trabalho de Silva, Kay e Perfect (1994), o IHO vem sendo amplamente utilizado como indicador da qualidade física e estrutural do solo (REICHERT; REINERT; BRAIDA, 2003; REICHERT; SUZUKI; REINERT, 2007; TORMENA; ARAÚJO; FIDALSKI, 2007; KAISER et al., 2009; SILVA et al., 2010; MOREIRA et al., 2014; DIAS et al., 2016; LIMA et al., 2019; OLIVEIRA et al., 2019; TAVANTTI et al., 2019; LI et al., 2020).

Além de permitir avaliar a qualidade do solo em um dado momento, a determinação do IHO como uma função da densidade do solo leva à obtenção de equações e de um diagrama (LETEY, 1985; SILVA; KAY; PERFECT, 1994), a partir dos quais se podem prever alterações na qualidade física do solo tanto em decorrência de sua compactação adicional quanto de sua recuperação estrutural. Assim, para solos com baixa densidade, a faixa de umidade correspondente ao IHO coincide com a água disponível (AD). Nessa situação, os limites superior e inferior do IHO são, respectivamente, as umidades na capacidade de campo $\left(\theta_{c c}\right)$ e no ponto de murcha permanente $\left(\theta_{\mathrm{PMP}}\right)$. Com o aumento da densidade, em certo ponto, com o solo na umidade correspondente à capacidade de campo, passará a ocorrer restrições de aeração, ponto esse em que a densidade atinge o valor crítico $\mathrm{Ds}_{\text {PAcrit }}$. De modo semelhante, com o solo na umidade correspondente ao ponto de murcha permanente, em certo ponto passará a ocorrer resistência à penetração restritiva ao crescimento radicular, atingindo-se aí o valor crítico de densidade $\mathrm{Ds}_{\text {RPcrit }}$. Assim, para Ds $>\mathrm{Ds}_{\text {PAcrit' }^{\prime}}$ o limite superior do IHO será a umidade na qual a porosidade de aeração assume um valor mínimo ou crítico $\left(\theta_{\text {PAcrit }}\right)$, inferior à umidade na capacidade de campo. Já para Ds 
$>\mathrm{DS}_{\mathrm{RP} \text { rit' }}$ O limite inferior do IHO será a umidade na qual a resistência à penetração assume um valor máximo ou crítico $\left(\theta_{\text {RPcrit }}\right)$ superior à umidade no ponto de murcha permanente. Por fim, com o solo se adensando ainda mais, a densidade poderia atingir um valor de densidade crítica ( $D s_{\mathrm{IHO}_{0}}$ ) em que deixaria de existir o IHO, pois, qualquer que fosse a umidade, haveria restrições devidas à aeração insuficiente, ou resistência à penetração seria excessiva, ou ambas.

Cabe ressaltar que esses valores críticos de densidade têm sido identificados em inúmeras situações de campo, sob diversos usos e manejos, indicando níveis de degradação física do solo que impõem às plantas condições limitantes ao seu pleno desenvolvimento mesmo frente a pequenas variações temporais e espaciais do conteúdo de água do solo, condições hídricas que a priori seriam adequadas (TORMENA; ARAÚJO; FIDALSKI, 2007; BENGOUGH et al., 2011). Conhecer, por meio do IHO, os limites críticos da densidade do solo auxilia na tomada de decisões diante das condições de manejo adotadas ou a serem adotadas em determinado solo (DIAS et al., 2016). Dessa forma, o IHO destaca-se como um moderno e importante indicador de qualidade física do solo (SILVA; KAY; PERFECT,1994; TORMENA; SILVA; LIBARDI, 1998; IMHOFF et al., 2001; LEÃO et al., 2004; TORMENA; ARAÚJO; FIDALSKI, 2007; DIAS et al., 2016; LIMA et al., 2019; OLIVEIRA et al., 2019; TAVANTTI et al., 2019; LI et al., 2020), utilizado em diferentes solos e sistemas de uso e manejo.

Diante do exposto, o presente estudo partiu da hipótese de que as áreas revegetadas com leguminosas arbóreas apresentam melhoria das condições físicas do solo quando comparadas à pastagem (área degradada) e que, com o passar dos anos, tendem a se aproximar da área sob floresta. Dessa maneira, o objetivo deste trabalho foi avaliar a eficiência da revegetação com as leguminosas arbóreas Acacia auriculiformis, Mimosa caesalpiniifolia e Inga edulis para a recuperação da qualidade física de um Argissolo Vermelho-Amarelo Distrófico típico, inicialmente sob pastagem degradada, utilizando como indicador o intervalo hídrico ótimo $(\mathrm{IHO})$ e as densidades críticas dele decorrentes. 


\section{MATERIAL E MÉTODOS}

A área experimental localiza-se no município de Conceição de Macabú, Norte Fluminense, na Fazenda Carrapeta ( $21^{\circ} 37^{\prime} \mathrm{S}$ e $\left.42^{\circ} 05^{\prime} \mathrm{W}\right)$. Pela classificação de Köppen, o clima da região é do tipo Am, quente e úmido, com temperatura média anual de $26^{\circ} \mathrm{C}$ e precipitação média anual de 1400 mm (GAMA-RODRIGUES et al., 2008). O relevo é forte ondulado, com declividade em torno de $35 \%$. O solo, classificado de acordo com - Sistema Brasileiro de Classificação de Solos (SANTOS et al., 2018), é um Argissolo Vermelho-Amarelo Distrófico típico, tendo como material de origem rochas graníticasgnáissicas que compõem o embasamento cristalino regional.

No referido sítio, cinco áreas sob diferentes coberturas vegetais foram estudadas. Três dessas áreas são talhões de $1500 \mathrm{~m}^{2}$, constituídas de plantios puros das espécies arbóreas de leguminosas Acacia auriculiformis (acácia), Mimosa caesalpiniifolia (sabiá) e Inga edulis (ingá), implantadas em dezembro de 1998 para fins de recuperação ambiental. As outras duas áreas, adjacentes aos plantios de leguminosas, têm como coberturas vegetais uma pastagem e uma capoeira. A pastagem, que representa a vegetação anterior ao plantio das espécies arbóreas, tem o predomínio de capimgordura (Melinis minutiflora), grama-pernambuco (Paspalum maritimum) e sapê (Imperata brasiliensis), sendo admitida como referência de área degradada por possuir pouca cobertura sobre o solo, em uma área total de 3,98 ha. A capoeira é um fragmento florestal de Mata Atlântica em sucessão secundária, com espécies em diferentes estádios sucessionais, estando há cerca de 50 anos sem remoção de árvores por ação antrópica, sendo admitida neste trabalho como referência de área preservada, com área de 10 ha. Para a amostragem de solo foi considerada uma parcela útil de $1500 \mathrm{~m}^{2}$ na parte central. Mesmo procedimento foi admitido para a área da pastagem (GAMARODRIGUES et al., 2008; GOMES; MARCIANO; FAUSTINO, 2018).

Em julho de 2015, amostras de solo com estrutura deformada e indeformada foram coletadas das camadas 0-0,10 e 0,10-0,20 m de profundidade, em seis pontos 
de coleta (repetições) de cada talhão, afastados 5 m entre si, na direção da maior declividade. Ambos os tipos de amostras foram utilizados por Gomes, Marciano e Faustino (2018) para caracterização química e física (Tabela 1). As amostras indeformadas foram coletadas em anéis metálicos de $53 \mathrm{~mm}$ de altura e $100 \mathrm{~cm}^{3}$ de volume, com um amostrador SondaTerra ${ }^{\circledR}$, sendo oito anéis por ponto de coleta (quatro por camada), totalizando 48 anéis por área e 240 anéis no total.

Tabela 1 - Caracterização química e física das camadas do Argissolo Vermelho-Amarelo, sob diferentes coberturas vegetais em Conceição de Macabú - RJ

\begin{tabular}{|c|c|c|c|c|c|c|c|c|c|c|c|}
\hline \multirow{2}{*}{$\begin{array}{l}\text { Cobertura } \\
\text { Vegetal }\end{array}$} & $\mathrm{pH}$ & $\mathbf{P}$ & C & $\mathbf{N}$ & $\mathrm{H}+\mathrm{Al}$ & $\mathrm{CTC}_{\text {efet }}$ & Ds & PT & Areia & Silte & Argila \\
\hline & $\mathrm{H}_{2} \mathrm{O}$ & $\mathrm{mg} \mathrm{kg}^{-1}$ & \multicolumn{2}{|c|}{$\mathrm{g} \mathrm{kg}^{-1}$} & \multicolumn{2}{|c|}{$\mathrm{cmol}_{\mathrm{c}} \mathrm{kg}^{-1}$} & $\mathrm{Mg} \mathrm{m}^{-3}$ & $m^{3} m^{-3}$ & & \multicolumn{2}{|l|}{$\mathrm{g} \mathrm{kg}^{-1}$} \\
\hline \multicolumn{12}{|c|}{$0-0,10 \mathrm{~m}$} \\
\hline Capoeira & 4,22 & 1,83 & 18,8 & 1,56 & 7,82 & 1,9 & 1,11 & 0,58 & 640 & 85 & 275 \\
\hline Pasto & 4,26 & 3,35 & 13,1 & 0,93 & 6,40 & 1,3 & 1,36 & 0,48 & 637 & 91 & 272 \\
\hline Acácia & 4,48 & 2,55 & 14,6 & 1,37 & 6,77 & 2,5 & 1,38 & 0,47 & 627 & 70 & 303 \\
\hline Ingá & 4,22 & 2,18 & 13,9 & 1,07 & 6,55 & 1,9 & 1,21 & 0,54 & 611 & 93 & 296 \\
\hline Sabiá & 4,26 & 2,63 & 16,0 & 1,36 & 7,77 & 2,2 & 1,25 & 0,52 & 604 & 97 & 299 \\
\hline \multicolumn{12}{|c|}{$0,10-0,20 \mathrm{~m}$} \\
\hline Capoeira & 4,12 & 1,18 & 12,2 & 1,10 & 7,48 & 1,4 & 1,09 & 0,58 & 599 & 94 & 307 \\
\hline Pasto & 4,18 & 0,63 & 11,3 & 0,86 & 7,07 & 1,1 & 1,27 & 0,52 & 533 & 110 & 357 \\
\hline Acácia & 4,34 & 1,63 & 11,1 & 1,00 & 6,62 & 1,7 & 1,47 & 0,44 & 510 & 96 & 394 \\
\hline Ingá & 4,28 & 1,25 & 10,8 & 1,01 & 6,57 & 1,5 & 1,28 & 0,51 & 536 & 108 & 356 \\
\hline Sabiá & 4,22 & 1,43 & 11,9 & 1,00 & 6,65 & 1,7 & 1,37 & 0,48 & 515 & 112 & 373 \\
\hline
\end{tabular}

Fonte: Gomes et al. (2018)

Em que: pH em água (1:2,5); P: fósforo - Extrator Mehlich-1; C: carbono - C orgânico determinado com dicromato de potássio por colorimetria; $\mathrm{N}$ total foi determinado pelo método Kjeldahl; $\mathrm{H}+\mathrm{Al}-$

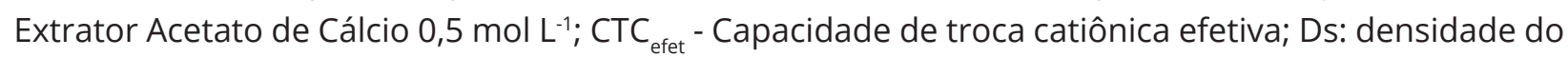
solo, PT: porosidade total; Areia, silte e argila: peneiramento + método da pipeta. Análises realizadas conforme o Manual de Métodos de Análise de Solo (TEIXEIRA et al., 2017).

Para cada área, os anéis de pontos vizinhos foram agrupados dois a dois (1 e 2; 3 e 4; 5 e 6) para formar três conjuntos de oito anéis por camada, procedendo-se a obtenção de uma curva de retenção de água para cada conjunto, com cada ponto da curva (tensão-umidade) advindo de um anel específico. Durante esse processo, 
as amostras que atingiam o equilíbrio nas câmaras de pressão, nas tensões 10, 33, 100, 500 e 1500 kPa, eram retiradas e utilizadas para a determinação da resistência à penetração (RP), conforme protocolo estabelecido por Silva, Kay e Perfect (1994). Para tal foi utilizado o penetrógrafo de bancada, com ponteira de $4 \mathrm{~mm}$ de diâmetro basal e semiângulo de $30^{\circ}$, com velocidade de penetração ajustada para $10 \mathrm{~mm} \mathrm{~min}{ }^{-1}$. Um computador acoplado ao aparelho registrou, a cada segundo, durante 240 segundos, em um curso de penetração de $40 \mathrm{~mm}$, os valores de resistência medidos por uma célula de carga. Para representar a resistência à penetração de cada amostra (RP, MPa) foi considerada a média dos referidos valores, com descarte daqueles iniciais, crescentes, anteriores ao atingimento de um patamar gráfico. Os dados foram ajustados ao modelo de Busscher (1990), permitindo a obtenção da curva de RP em função da umidade $(\theta)$ e densidade (Ds) (SILVA; KAY; PERFECT, 1994), conforme Equação (1):

$$
R P=a D s^{b} \theta^{c}
$$

em que: a, b e c são constantes de ajuste, estimadas com o auxílio do suplemento "solver" do programa Microsoft Office Excel 2010, pelo método dos mínimos quadrados. Como o agrupamento de anéis de pontos vizinhos, dois a dois, em cada área foram obtidas três curvas de RP por camada de solo.

Os dados de retenção de água, originalmente obtidos por Gomes, Marciano e Faustino (2018), foram ajustados ao modelo de Van Genuchten (1980), de acordo com a Equação (2):

$\theta=\theta_{r}+\left(\theta_{s}-\theta_{r}\right) /\left(1+\alpha \cdot \tau^{n}\right)^{m}$

em que: $\theta_{s}$ é a umidade volumétrica na saturação $\left(\mathrm{m}^{3} \mathrm{~m}^{-3}\right)$, assumida como correspondente à porosidade total (PT); $\theta_{r}$ é a umidade volumétrica residual $\left(\mathrm{m}^{3} \mathrm{~m}^{-3}\right) ; a\left(\mathrm{kPa}^{-1}\right)$ e $\mathrm{m}$ e $\mathrm{n}$ (adimensionais) são parâmetros empíricos do modelo, com $\mathrm{m}$ dependente de $\mathrm{n}(\mathrm{m}=$ $1-1 / n)$. Para que as equações fossem representativas da diversidade estrutural do solo, a densidade do solo (Ds) foi inserida no modelo, por meio da substituição de $\theta_{r}$ e $\theta_{s}$ por expressões equivalentes, quais sejam: $\theta_{r}=U_{r} D s / D a$ e $\theta_{s}=P T=1-D s / D p$. Nessas expressões, $U_{r}$ é a umidade residual gravimétrica $\left(\mathrm{kg} \mathrm{kg}^{-1}\right)$, Da é a densidade da água (assumida como $1000 \mathrm{~kg} \mathrm{~m}^{-3}$ ) e Dp é a densidade de partículas (assumida como $2650 \mathrm{~kg}$ $\mathrm{m}^{-3}$ ). O ajuste foi feito utilizando o suplemento "solver" do Microsoft Office Excel 2010, sendo os parâmetros de ajuste $U_{r^{\prime}}$ a e m estimados iterativamente pelo método dos mínimos quadrados. 
Na Tabela 2, constam os parâmetros de ajuste das Equações 1 e 2, que representam, respectivamente, as curvas de resistência à penetração e de retenção de água no solo.

Tabela 2 - Parâmetros de ajuste da equação de Busscher e da equação de Van Genuchten nas diferentes coberturas vegetais em Conceição de Macabú - RJ

\begin{tabular}{|c|c|c|c|c|c|c|c|}
\hline \multirow[t]{2}{*}{ Cobertura Vegetal } & \multicolumn{3}{|c|}{$\begin{array}{c}\text { Parâmetros de } \\
\text { Bussher (Equação 1) }\end{array}$} & \multicolumn{4}{|c|}{$\begin{array}{l}\text { Parâmetros de Van } \\
\text { Genuchten (Equação 2) }\end{array}$} \\
\hline & $a$ & $\mathbf{b}$ & c & $U_{r}$ & alfa & $\mathbf{m}$ & $\mathbf{n}$ \\
\hline & \multicolumn{7}{|c|}{$0-0,10 \mathrm{~m}$} \\
\hline Capoeira & 0,001 & 4,442 & $-3,493$ & 0,140 & 1,641 & 0,509 & 2,037 \\
\hline Pasto & 0,225 & 5,618 & 0,157 & 0,150 & 0,938 & 0,368 & 1,582 \\
\hline Acácia & 2,094 & 0,100 & $-0,278$ & 0,141 & 4,611 & 0,289 & 1,407 \\
\hline Ingá & 0,030 & 5,208 & $-1,477$ & 0,139 & 3,571 & 0,342 & 1,520 \\
\hline \multirow[t]{2}{*}{ Sabiá } & 0,008 & 7,725 & $-2,286$ & 0,168 & 2,851 & 0,374 & 1,597 \\
\hline & \multicolumn{7}{|c|}{$0,10-0,20 \mathrm{~m}$} \\
\hline Capoeira & 0,023 & 1,470 & $-2,095$ & 0,157 & 1,394 & 0,449 & 1,815 \\
\hline Pasto & 0,001 & 4,583 & $-4,063$ & 0,155 & 1,611 & 0,362 & 1,569 \\
\hline Acácia & 0,000 & 10,247 & $-4,800$ & 0,153 & 2,270 & 0,260 & 1,352 \\
\hline Ingá & 0,033 & 8,570 & $-1,505$ & 0,178 & 1,428 & 0,365 & 1,575 \\
\hline Sabiá & 0,228 & 3,307 & $-1,270$ & 0,191 & 0,927 & 0,381 & 1,615 \\
\hline
\end{tabular}

Fonte: Autores (2020)

Em que: $a, b, c, U_{r}$ alfa, m, e $n$ = parâmetros de ajuste das Equações 1 e 2, estimadas com o auxílio do suplemento "solver" do programa Microsoft Office Excel 2010, pelo método dos mínimos quadrados.

A partir da curva de retenção (Equação 2), os valores de umidade na capacidade de campo $\left(\theta_{C C}\right)$ e no ponto de murcha permanente $\left(\theta_{\mathrm{PMP}}\right)$, delimitadores da faixa de água disponível às plantas (AD) e equivalentes às tensões 10 e 1500 kPa, respectivamente, foram estimados, para cada área e camada, em função de Ds. Assumindo-se, para a porosidade livre de água, o valor mínimo crítico à aeração correspondente a 10 $\%$ do volume do solo, a umidade em tal condição $\left(\theta_{\mathrm{PA}=10 \%}\right)$ foi obtida a partir da PT, subtraindo-se $0,10 \mathrm{~m}^{3} \mathrm{~m}^{-3}\left(\theta_{P A=10 \%}=P T-0,10\right)$, também expresso em função de Ds. Da mesma forma, assumindo-se, para a resistência mecânica do solo, o valor máximo crítico à penetração de raízes correspondente a 3,0 MPa (UNGER; KASPAR, 1994; 
SERAFIM et al., 2013), a umidade que representa esta condição $\left(\theta_{\mathrm{RP}=3 \mathrm{MPa}}\right)$ foi obtida a partir da Equação 1, também em função de Ds.

A partir dos limites críticos acima mencionados foi determinado o intervalo hídrico ótimo (IHO) e os valores de densidade crítica às plantas. Matematicamente, o IHO é a diferença entre dois valores-limite de umidade, um superior e um inferior. Como limite superior considera-se o menor valor entre $\theta_{c C}$ e $\theta_{P A=10 \%}$, sendo que no ponto em que as duas umidades tornam-se equivalentes identifica-se a densidade do solo crítica à aeração $\left(D_{S C_{P A}}\right)$. Como limite inferior considera-se o maior valor entre $\theta_{P M P}$ e $\theta_{\mathrm{RP}_{3} 3 \mathrm{MPa}^{\prime}}$ sendo que no ponto de equivalência entre as duas umidades identifica-se a densidade do solo crítica à penetração das raízes $\left(\operatorname{Dsc}_{\mathrm{RP}}\right)$. No ponto em que os limites superior e inferior de umidade se igualaram, O IHO tornou-se zero e identificou-se, então, a densidade do solo crítica ao crescimento vegetal (Dsc ou Dsc ${ }_{1 \text { HO }}$ ). Graficamente, o IHO é representado pela área entre as funções representativas das umidades críticas superior e inferior.

Os pressupostos da estatística paramétrica (distribuição normal de resíduos e homogeneidade de variâncias) foram testados pelo teste de Kolmogorov-Smirnov e Lilliefors. Não houve necessidade de se fazer a transformação dos dados. De forma semelhante a outros trabalhos realizados na presente área de estudo (GAMARODRIGUES et al., 2008; COSTA et al., 2014; GOMES; MARCIANO; FASUTINO, 2018), a análise estatística foi feita admitindo-se um delineamento inteiramente casualizado. Para a análise estatística foram considerados, ainda, os tratamentos em um esquema de parcelas subdivididas, com as coberturas vegetais como parcelas e as duas camadas de amostragem de solo como subparcelas, e os pontos de coleta como repetições. A análise estatística foi realizada usando o programa "Assistat" (SILVA, 2014), incluindose a análise de variância experimental, a comparação de médias pelo teste de Tukey a $5 \%$ de probabilidade. 


\section{RESULTADOS E DISCUSSÃO}

Na Tabela 3, são apresentados os valores das variáveis físicas que delimitam o $\mathrm{IHO}$, quais sejam: umidade no ponto de aeração crítica $\left(\theta_{\mathrm{PA}=10 \%}\right) ;$ umidade na capacidade de campo $\left(\theta_{c c}\right)$; umidade no ponto de murcha permanente $\left(\theta_{\text {PMP }}\right)$; e umidade no ponto de resistência à penetração crítica $\left(\theta_{\mathrm{RP}=3 \mathrm{MPa}}\right)$. Na Tabela 3, também são apresentados os valores de água disponível (AD) e do intervalo hídrico ótimo (IHO) e, ainda, os valores de densidade do solo que são críticos para a porosidade de aeração $\left(\operatorname{Dsc}_{P_{A}}\right.$ ) e para a resistência à penetração $\left(\mathrm{Dsc}_{\mathrm{RP}}\right)$ e em que o intervalo hídrico ótimo torna-se zero $\left(\mathrm{Dsc}_{1 \mathrm{HO}}\right)$.

Cabe ressaltar que os valores de umidade $\left(\theta_{\mathrm{PA}=10 \% ;} \theta_{\mathrm{CC} ;} \theta_{\mathrm{PMP}} ; \theta_{\mathrm{RP}=3 \mathrm{MPa}}\right)$ e de amplitude hídrica (AD; IHO) da Tabela 3 foram obtidos considerando-se os valores médios de Ds para cada cobertura vegetal e camada de solo estudada, os quais constam na Tabela 1. Em relação às umidades que determinam o limite superior da $A D$ e/ou do IHO, a máxima umidade que preserva uma porosidade de aeração assumida como não restritiva às plantas $\left(\theta_{\mathrm{PA}=10 \%}\right.$, Tabela 3$)$ foi, em ambas as camadas, maior sob capoeira e menor sob acácia (e menor também sob pasto, na camada 0-0,10 m). Esse resultado é reflexo direto das diferenças de porosidade total (Tabela 1), a partir da qual $\theta_{\mathrm{PA}=10 \%}$ é matematicamente obtida. Como todos os valores de $\theta_{\mathrm{PA}=10 \%}$ foram maiores que os de umidade na capacidade de campo $\left(\theta_{c c}\right)$, em nenhuma situação houve condições de restrição de aeração do solo, mesmo nas coberturas vegetais com as maiores densidades médias. Para a $\theta_{c c^{\prime}}$ as diferenças entre as coberturas vegetais foram aproximadamente opostas às verificadas para $\theta_{\mathrm{PA}=10 \%}$ com os menores valores ocorrendo sob capoeira, em ambas as camadas, e os maiores sob pasto, na camada 0-0,10 m, e sob sabiá e acácia, na camada 0,10-0,20 m. A relação direta entre densidade do solo (Tabela 1) e $\theta_{c c}$ revela que a compactação tem efeito favorável para o armazenamento de água no solo. 
Faustino, L. L.; Marciano, C. R. | 670

Tabela 3 - Valores médios de umidade do solo nas diferentes coberturas vegetais em Conceição de Macabú - RJ

\begin{tabular}{|c|c|c|c|c|c|c|c|c|c|}
\hline $\begin{array}{c}\text { Cobertura } \\
\text { Vegetal }\end{array}$ & $\theta_{\mathrm{PA}=10 \%}$ & $\boldsymbol{\theta}_{\mathrm{cc}}$ & $\theta_{\mathrm{PMP}}$ & $\boldsymbol{\theta}_{\mathrm{RP}=3 \mathrm{MPa}}$ & $A D$ & IHO & $\mathrm{Dsc}_{\mathrm{PA}}$ & $\mathrm{DSC}_{\mathrm{RP}}$ & Dsc $_{\text {Iно }}$ \\
\hline \multicolumn{10}{|c|}{$0-0,10 \mathrm{~m}$} \\
\hline Capoeira & $0,48 \mathrm{aA}$ & $0,17 \mathrm{cB}$ & 0,14 & $0,14 \mathrm{aA}$ & 0,03 & $0,03 \mathrm{bB}$ & 1,78 & 1,99 & 1,99 \\
\hline Pasto & $0,39 c B$ & $0,24 \mathrm{aA}$ & 0,16 & $0,17 \mathrm{aA}$ & 0,08 & $0,07 \mathrm{aA}$ & 1,77 & 1,32 & 1,63 \\
\hline Acácia & $0,38 \mathrm{cA}$ & $0,21 a b B$ & 0,15 & $0,17 \mathrm{aB}$ & 0,06 & $0,04 a b A$ & 1,83 & 1,27 & 1,48 \\
\hline Ingá & $0,44 \mathrm{bA}$ & $0,20 \mathrm{bB}$ & 0,14 & $0,14 \mathrm{aB}$ & 0,06 & $0,06 a b A$ & 1,79 & 1,47 & 1,57 \\
\hline Sabiá & $0,43 \mathrm{bA}$ & $0,22 \mathrm{abB}$ & 0,17 & $0,17 \mathrm{aB}$ & 0,05 & $0,05 a b A$ & 1,73 & 1,29 & 1,46 \\
\hline Média & 0,42 & 0,20 & $0,15 \mathrm{~B}$ & 0,16 & 0,05 B & 0,05 & $1,78 \mathrm{~A}$ & $1,47 \mathrm{~A}$ & $1,62 \mathrm{~A}$ \\
\hline \multicolumn{10}{|c|}{$0,10-0,20 \mathrm{~m}$} \\
\hline Capoeira & $0,49 a A$ & $0,21 \mathrm{cA}$ & 0,16 & $0,16 \mathrm{dA}$ & 0,05 & $0,05 \mathrm{aA}$ & 1,70 & 1,92 & 1,92 \\
\hline Pasto & $0,42 \mathrm{bA}$ & 0,23 bcA & 0,16 & $0,17 \mathrm{cdA}$ & 0,07 & $0,06 \mathrm{aA}$ & 1,75 & 1,20 & 1,83 \\
\hline Acácia & $0,34 \mathrm{~dB}$ & $0,26 \mathrm{aA}$ & 0,17 & $0,23 \mathrm{aA}$ & 0,09 & $0,03 \mathrm{aA}$ & 1,77 & 1,24 & 1,55 \\
\hline Ingá & $0,42 \mathrm{bB}$ & $0,25 \mathrm{abA}$ & 0,18 & $0,19 \mathrm{bcA}$ & 0,07 & $0,06 \mathrm{aA}$ & 1,69 & 1,25 & 1,54 \\
\hline Sabiá & $0,38 \mathrm{cB}$ & $0,26 \mathrm{aA}$ & 0,20 & $0,22 \mathrm{abA}$ & 0,07 & $0,04 \mathrm{aA}$ & 1,68 & 1,06 & 1,47 \\
\hline Média & 0,41 & 0,24 & $0,17 \mathrm{~A}$ & 0,19 & $0,07 \mathrm{~A}$ & 0,05 & $1,71 \mathrm{~B}$ & $1,33 \mathrm{~B}$ & $1,65 \mathrm{~A}$ \\
\hline \multicolumn{10}{|c|}{ 0-0,20 m (Média das camadas) } \\
\hline Capoeira & 0,48 & 0,19 & $0,15 b$ & 0,15 & $0,04 \mathrm{~b}$ & 0,04 & $1,74 a b$ & $1,96 \mathrm{a}$ & $1,95 \mathrm{a}$ \\
\hline Pasto & 0,40 & 0,23 & $0,16 a b$ & 0,17 & $0,07 a b$ & 0,07 & $1,76 a b$ & $1,26 b$ & $1,73 a b$ \\
\hline Acácia & 0,36 & 0,24 & $0,16 a b$ & 0,20 & $0,08 a$ & 0,04 & $1,80 \mathrm{a}$ & $1,25 b$ & $1,51 \mathrm{bc}$ \\
\hline Ingá & 0,43 & 0,23 & $0,16 a b$ & 0,17 & $0,06 a b$ & 0,06 & $1,74 a b$ & $1,36 b$ & $1,55 b c$ \\
\hline Sabiá & 0,40 & 0,24 & $0,18 \mathrm{a}$ & 0,19 & $0,06 a b$ & 0,04 & $1,71 b$ & $1,18 b$ & $1,47 \mathrm{c}$ \\
\hline Méd. Geral & 0,42 & 0,22 & 0,16 & 0,17 & 0,06 & 0,05 & 1,75 & 1,40 & 1,64 \\
\hline CV-a (\%) & 3,15 & 6,07 & 8,13 & 8,17 & 32,02 & 31,82 & 1,98 & 8,31 & 7,73 \\
\hline CV-b (\%) & 2,83 & 4,35 & 7,12 & 7,39 & 22,42 & 24,24 & 1,32 & 8,30 & 7,04 \\
\hline
\end{tabular}

Fonte: Autores (2020)

Em que: $\theta_{P A=10 \%}=$ valores de umidade do solo no ponto de aeração crítica; $\theta_{c c}=$ valores de umidade do solo no ponto capacidade de campo; $\theta_{\mathrm{PMP}}=$ valores de umidade do solo no ponto de murcha permanente; $\theta_{\mathrm{RP}=3 \mathrm{MPa}}=$ valores de umidade do solo no ponto de resistência à penetração crítica; $A D$ = valores de água disponível; $\mathrm{IHO}$ = intervalo hídrico ótimo; $\mathrm{DSC}_{\mathrm{PA}}=$ densidade do solo crítica para a porosidade de aeração; $\mathrm{DSC}_{\mathrm{RP}}=$ densidade do solo crítica para a resistência à penetração; $\mathrm{DSC}_{\mathrm{HHO}}=$ densidade do solo crítica, em que o intervalo hídrico ótimo torna-se zero, correspondentes à condição média de densidade de cada área e camada. Obs. 1: Para cada coluna, médias seguidas de mesma letra maiúscula (que compara camadas) ou de mesma letra minúscula (que compara coberturas vegetais), não diferem entre si pelo teste Tukey $(p \leq 0,05)$. Obs. 2: CV-a e CV-b são, respectivamente, os coeficientes de variação obtidos na análise de variância para parcela e subparcela. 
Quanto às umidades determinantes do limite inferior da $A D$ e/ou do $\mathrm{IHO}$, para a média das duas camadas, a umidade no ponto de murcha permanente $\left(\theta_{\mathrm{PMP}}\right.$ Tabela 3) foi menor sob capoeira e maior sob sabiá. Tal qual ocorreu com a $\theta_{c C^{\prime}}$ isso é reflexo da dependência matemática entre umidade volumétrica e densidade do solo, que inclusive, no presente trabalho, está incorporada à Equação (2) $\left(\theta_{s}=1-D s / D p ; \theta_{r}=U_{r}\right.$ $D s / D a)$. Cabe ressaltar que as diferenças entre coberturas vegetais foram mais sutis para $\theta_{\text {PMP }}$ que para $\theta_{C C^{\prime}}$ o que decorre da retenção de água sob tensões mais elevadas depender menos da estrutura do solo e mais da superfície específica das partículas. Para a mínima umidade que previne a ocorrência de resistência à penetração assumida como restritiva às plantas $\left(\theta_{\mathrm{RP}=3 \mathrm{MPa}}\right)$, nas duas camadas de solo estudadas, os menores valores ocorreram sob capoeira e os maiores sob sabiá e acácia. Para $\theta_{\mathrm{RP}=3 \mathrm{MPa}^{\prime}}$ como para as demais umidades-padrão estudadas, os valores da Tabela 3 demonstram ter relação direta com os valores de densidade do solo (Tabela 1). Os valores de $\theta_{\mathrm{RP}=3 \mathrm{MPa}}$ foram maiores que os de $\theta_{\text {PMP }}$ para o solo sob pasto e acácia, em ambas as camadas, e também sob ingá e sabiá, apenas na camada 0,10-0,20 m. Esse resultado indica, para a condição média de densidade do solo, a ocorrência de restrições mecânicas ao crescimento radicular mesmo estando a umidade acima do PMP.

Em relação às faixas hídricas estudadas, para a média das duas camadas, a AD foi menor sob capoeira e maior sob acácia, com as demais coberturas não se distinguindo de uma ou da outra (Tabela 3). Klein e Libardi (2002) verificaram que um Latossolo Vermelho sob mata apresentou porosidade responsável pela retenção de água disponível às plantas menor que sob cultivo agrícola, associando tal resultado à maior compactação do solo nas áreas cultivadas. Na camada 0,10-0,20 m, o IHO não diferiu entre as coberturas vegetais, mas na camada $0-0,10 \mathrm{~m}$ foi menor sob capoeira e maior sob pasto, ambas sem diferir das demais coberturas. Esse resultado sugere, para a condição média de densidade do solo, que a ocorrência de restrições mecânicas ao crescimento radicular nas áreas antropizadas, conforme mencionado acima, poderiam estar sendo compensadas pelo incremento na disponibilidade 
hídrica. Essa seria uma conclusão controversa, uma vez que o valor de RP restritivo às plantas adotado para a obtenção do IHO não leva em conta diferenças entre as espécies. Nesse caso, as espécies mais sensíveis estariam sendo prejudicadas e, com isso, prejudicado também ficaria o equilíbrio ecológico.

Tanto a amplitude da AD (0,03 a 0,08 $\mathrm{m}^{3} \mathrm{~m}^{-3}$, na camada 0-0,10 m, e 0,05 a 0,09 $\mathrm{m}^{3} \mathrm{~m}^{-3}$, na 0,10-0,20 m) quanto a do IHO $\left(0,03\right.$ a 0,07 $\mathrm{m}^{3} \mathrm{~m}^{-3}$, na camada 0-0,10 $\mathrm{m}$, e 0,03 a 0,06 $\mathrm{m}^{3} \mathrm{~m}^{-3}$, na 0,10-0,20 m) foram baixas (Tabela 3), mas podem ser consideradas naturais para o solo em questão. Leão et al. (2004), trabalhando com sistemas de pastejo contínuo e rotacionado, encontram uma amplitude total de variação do IHO de 0 até $0,1482 \mathrm{~m}^{3} \mathrm{~m}^{-3}$.

Nas Figuras 1 e 2, correspondentes, respectivamente, às camadas 0-0,10 e 0,100,20 m, são apresentadas as mesmas umidades $\left(\theta_{\mathrm{PA}=10 \%} ; \theta_{\mathrm{CC}} ; \theta_{\mathrm{PMP}} ; \theta_{\mathrm{RP}=3 \mathrm{MPa}}\right)$ e amplitudes hídricas $(A D ; I H O)$ que constam na Tabela 3. Aqui, essas umidades e amplitudes hídricas são expressas como variáveis em função da densidade, abrangendo toda a faixa de densidade obtida a partir das 24 amostras indeformadas coletadas em anéis em cada cobertura vegetal e camada de solo, não sendo correspondentes apenas à condição média de compactação representada pelos valores médios de densidade que constam na Tabela 1. Nas Figuras 1 e 2, a área hachurada representa graficamente o IHO e mostra sua amplitude de acordo com o aumento da Ds. Em relação ao limite superior do IHO, observa-se que, para todas as amostras das duas camadas de solo sob as cinco coberturas vegetais estudadas, este foi sempre correspondente à umidade na capacidade de campo $\left(\theta_{C C}\right)$. O valor de $\theta_{P A=10 \%}$ foi sempre maior que $\theta_{C C^{\prime}}$ podendo-se estimar os valores de densidade em que essa igualdade ocorreria e nos quais a aeração passaria a ser crítica às plantas ( $\mathrm{DSC}_{\mathrm{PA}}$ ). Conforme consta na Tabela

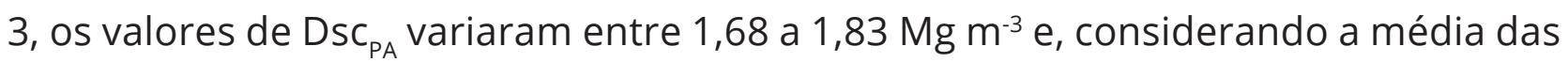
duas camadas estudadas, foi maior sob acácia e menor sob sabiá, ambas sem diferir das demais coberturas vegetais. Ressalta-se que esses valores estão bastante acima dos maiores valores de Ds observados na prática, que na camada 0-0,10 e 0,10- 
0,20 m foi para a área da acácia (1,38 $\mathrm{Mg} \mathrm{m}^{-3}$ e 1,47 $\mathrm{Mg} \mathrm{m}^{-3}$, respectivamente). Isso evidencia que, mesmo com estrutura degradada, este solo não apresenta problemas de aeração, o que se justifica por sua textura franco-argilosa, com alto teor de areia (Tabela 1), resultado que corrobora os encontrados por Silva, Kay e Perfect (2004), em que, nos solos de textura arenosa, o limite superior do IHO foi sempre a $\theta_{c c}$.

Quanto ao limite inferior do IHO, foram identificadas três situações ou casos distintos. O primeiro caso ocorreu para as áreas da capoeira, em ambas as camadas, e do ingá, na 0-0,10 m, verificando-se que mesmo nas maiores densidades observadas a $\theta_{P M P}$ foi sempre o limite inferior do IHO, evidenciando ausência das mencionadas restrições mecânicas ao crescimento radicular. O segundo caso ocorreu para as áreas da acácia e pasto, em ambas as camadas, e também para as áreas do sabiá e ingá, na camada 0,10-0,20 m, verificando-se que o limite inferior do IHO foi sempre determinado, desde as menores densidades, pela umidade em que a resistência à penetração é crítica $\left(\theta_{\mathrm{RP}=3 \mathrm{MPa}}\right)$. Isso caracteriza uma situação de compactação do solo em que há restrições mecânicas ao crescimento radicular mesmo com o solo na faixa de umidade da água disponível. No terceiro caso, verificado para a área do sabiá na camada 0-0,10 m, o IHO se inicia, nas menores densidades, tendo como limite inferior do IHO a umidade no ponto de murcha permanente $\left(\theta_{\mathrm{PMP}}\right)$, mas com o incremento da Ds a $\theta_{\mathrm{RP}=3 \mathrm{MPa}}$ passa a ser esse limite inferior, indicando que, na faixa de água disponível, há, nessas camadas, porções do solo com e outras sem restrições mecânicas às raízes.

Ainda a respeito ao limite inferior do IHO, foram estimados os valores críticos de densidade $\mathrm{DSC}_{\mathrm{RP}}$ em que $\theta_{\mathrm{PMP}}$ e $\theta_{\mathrm{RP}=3 \mathrm{MPa}}$ seriam iguais (Tabela 3). Para os dois primeiros casos mencionados no parágrafo anterior (respectivamente, as situações de ausência e de presença de restrições mecânicasàs raízes), esses valores de $D_{S C_{R P}}$ estiveram fora da faixa de Ds observada no campo para cada cobertura vegetal e camada de solo em questão. Da primeira situação verifica-se que os valores estimados de $\operatorname{Dsc}_{\mathrm{RP}}$ ficaram acima da faixa de Ds observada nas amostras coletadas, sendo 1,99 e 1,92 $\mathrm{Mg} \mathrm{m}^{-3}$ para a capoeira (camada 0-0,10 e 0,10-0,20 m, respectivamente) e 1,47 Mg m³ o ingá (camada 
0-0,10 m). Para a segunda situação, verifica-se que a estimativa de DSC $_{R P}$ resultou em valores abaixo da faixa de Ds observada nas amostras coletadas. Os valores de $\mathrm{Dsc}_{\mathrm{RP}}$ foram 1,32 e 1,27 $\mathrm{Mg} \mathrm{m}^{-3}$ para o pasto e acácia, respectivamente, na camada 0-0,10 m, e ficaram entre 1,06 e 1,25 Mg m³ para o pasto e três leguminosas, na camada 0,10-0,20 $\mathrm{m}$. Nesses casos, a diminuição das condições restritivas às plantas depende de que os atuais valores médios de densidade (Tabela 1) sejam reduzidos para valores inferiores aos de $\operatorname{Dsc}_{\mathrm{RP}}$ (Tabela 3), o que está bem longe de ocorrer. Para a terceira situação, de compactação intermediária (sabiá, na camada 0-0,10 m), o valor de Dsc $_{\mathrm{RP}}$ estimado foi 1,27 $\mathrm{Mg} \mathrm{m}^{-3}$ (Tabela 3), o qual se insere na faixa de Ds observada para essa cobertura vegetal e camada de solo (Figura 1), evidenciando que condições restritivas às plantas ocorrem em apenas parte do volume de solo.

Ainda acerca dos resultados de $\mathrm{DSC}_{\mathrm{RP}}$ acima descritos, verificou-se, para a média das duas camadas estudadas, que esse valor crítico de densidade foi estatisticamente maior para a capoeira em relação às demais coberturas. Isso revela que, nesse aspecto, uma eventual recuperação estrutural do solo após 17 anos da revegetação foi pouco expressiva ou mesmo inexistente.

$\mathrm{O}$ IHO torna-se nulo quando a umidade que determina seu limite inferior $\left(\theta_{\mathrm{RP}=3 \mathrm{MPa}}\right.$ ou $\left.\theta_{P M P}\right)$ se iguala (ou supera) a umidade que determina o limite superior $\left(\theta_{\mathrm{PA}=10 \%}\right.$ ou $\left.\theta_{c c}\right)$, identificando-se, nesse ponto, a densidade do solo crítica ao crescimento vegetal (Dsc ${ }_{{ }_{\mathrm{HHO}}}$ ) (LEÃO et al., 2004). Para a faixa de Ds observada na prática em cada cobertura vegetal e camada de solo, essa possibilidade $(\mathrm{IHO}=0)$ não se concretizou em nenhum caso (Tabela 3). A comparação entre as coberturas vegetais quanto à $\mathrm{Dsc}_{\mathrm{IHO}_{\mathrm{H}}}$ revelou, para a média das duas camadas estudadas, superioridade da capoeira (1,95 $\left.\mathrm{Mg} \mathrm{m}^{-3}\right)$, condição intermediária da pastagem $\left(1,73 \mathrm{Mg} \mathrm{m}^{-3}\right)$, e valores mais baixos para as leguminosas arbóreas (entre 1,47 e 1,64 $\mathrm{Mg} \mathrm{m}^{-3}$ ). Valores mais altos das três densidades críticas às plantas estudadas ( $\mathrm{DsC}_{\mathrm{PA}} ; \mathrm{DsC}_{\mathrm{RP}^{\prime}}$ Dsc $\mathrm{IHO}_{\mathrm{H}}$ ) indicam resiliência do solo frente ao processo de degradação pela compactação. 
Os resultados acima descritos, acerca dos limites do $\mathrm{IHO}$ e das densidades críticas deles resultantes, evidenciam que, para a faixa de Ds observada no solo sob leguminosas arbóreas e também sob pasto, o IHO foi menor que a AD em grande parte dos casos, sendo que o fator que determinou tal inferioridade foi sempre a elevada resistência mecânica do solo. A constatação de que a RP é o principal fator físico limitante às plantas também foi feita por Bengough et al. (2011) para solos de diferentes texturas e sob diversas condições de manejo.

Figura 1 - Curva da variação do conteúdo volumétrico de água em um Argissolo Vermelho-Amarelo sob diferentes coberturas vegetais em Conceição de Macabú - RJ. (PT: porosidade total; $\theta_{\mathrm{PA}=10 \%}$ : umidade volumétrica em que o limite crítico porosidade de aeração é de $10 \%$; $\theta_{\text {cc: }}$ umidade volumétrica no limite crítico de capacidade de campo; $\theta_{\mathrm{PMP}}$ : umidade volumétrica no limite crítico do ponto de murcha permanente; $\theta_{\mathrm{RP}=3 \mathrm{MPA}}:$ umidade volumétrica em que o limite crítico da resistência do solo à penetração é de 3,0 MPa) em função da densidade do solo na camada 0-0,10 m. A área hachurada representa o intervalo hídrico ótimo (IHO); as linhas pontilhadas representam o ponto médio calculado da Tabela 3

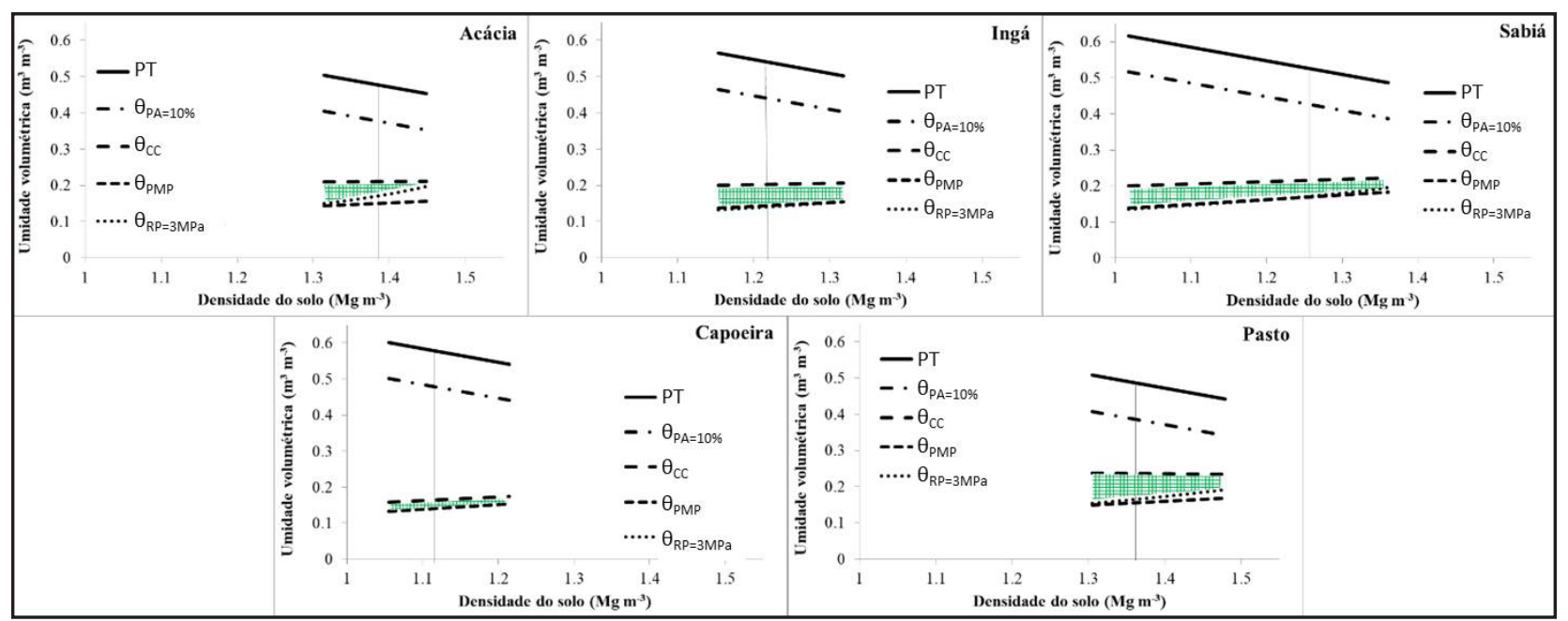

Fonte: Autores (2020) 
As áreas revegetadas e o pasto já haviam sido no passado áreas cultivadas, de modo que o manejo então adotado (para o cultivo do café, o pastejo de animais e mesmo para a implantação dos atuais sistemas florestais com leguminosas) pode ter sido a origem da atual compactação e ocorrência de restrições mecânicas ao desenvolvimento radicular, as quais definem o limite inferior do IHO.

Figura 2 - Curva da variação do conteúdo volumétrico de água em um Argissolo Vermelho-Amarelo sob diferentes coberturas vegetais em Conceição de Macabú - RJ. (PT: porosidade total; $\theta_{\mathrm{PA}=10 \%}$ : umidade volumétrica em que o limite crítico porosidade de aeração é de $10 \%$; $\theta_{c c}$ : umidade volumétrica no limite crítico de capacidade de campo; $\theta_{\mathrm{PMP}}$ : umidade volumétrica no limite crítico do ponto de murcha permanente; $\theta_{\mathrm{RP}=3 \mathrm{MPA}}$ : umidade volumétrica em que o limite crítico da resistência do solo à penetração é de 3,0 MPa) em função da densidade do solo na camada 10-0,20 m. A área hachurada representa o intervalo hídrico ótimo (IHO); as linhas pontilhadas representam o ponto médio calculado da Tabela 3

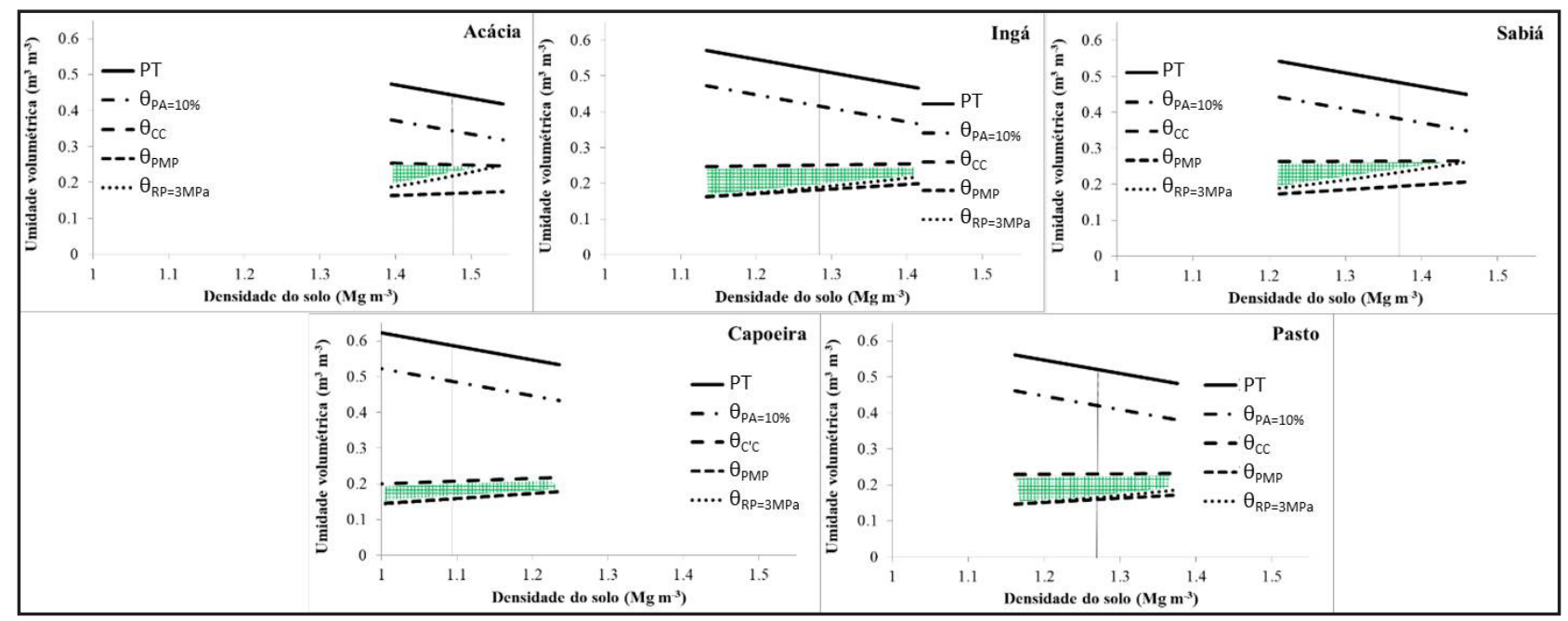

Fonte: Autores (2020)

Em sistemas de adição contínua de matéria orgânica, como no presente caso, era de se esperar uma melhoria da estrutura do solo de modo a aumentar, por um lado, a porosidade total e a umidade na qual a porosidade de aeração é crítica $\left(\theta_{\text {PAcrit }}\right)$, 
e a diminuir, por outro lado, a umidade na qual a resistência à penetração é também crítica $\left(\theta_{\mathrm{RPcrit}}\right)$, o que levaria ao aumento do IHO. Em seu estudo, Sharma e Bhushan (2001) observaram tal evidência, de que a adição de biomassa ao solo provocou aumento na $\theta_{\text {PAcrit }}$ e diminuição na $\theta_{\text {RPritit }}$ com consequente aumento do IHO. Os autores encontraram valores IHO 1,7 vezes maiores nos tratamentos em que foi aplicada biomassa vegetal, em relação à testemunha sem aplicação de biomassa. Isso contrasta com os resultados deste estudo, no qual se esperava que as áreas revegetadas pelas leguminosas se assemelhassem mais à capoeira, principalmente na camada 0-0,10 m, na qual a influência da matéria orgânica é maior.

Para a área da capoeira, nas duas camadas, e do ingá, na 0,10-0,20 m, o IHO é igual à "água disponível", sendo essa igualdade indicadora de solo com qualidade física favorável ao crescimento das plantas. Nesse caso, toda a água entre $\theta_{c c}$ e $\theta_{\text {PMP }}$ pode ser utilizada pelas plantas sem restrições físicas para as raízes, o que potencializa a capacidade do sistema em mitigar o deficit hídrico (SERAFIM et al., 2013). Ocorre que o solo da capoeira apresentou valores muito baixos de $A D$ e, consequentemente, de IHO (Tabela 3), com média das duas camadas de $0,036 \mathrm{~m}^{3} \mathrm{~m}^{-3}$. Lopes (2017), avaliando os atributos hidrodinâmicos e da afinidade água-solo em agregados da área do presente estudo e coletados na mesma ocasião, também em junho de 2015, encontrou níveis de hidrofobicidade maiores no solo sob capoeira que sob as demais coberturas vegetais. A autora relata que, em certas situações, a tentativa de associar atributos relacionados à dinâmica da água com atributos estruturais do solo não foi bem-sucedida, sendo esse insucesso decorrente do fato de se admitirem como verdadeiros e universais certos aspectos específicos da afinidade água-solo, negligenciando, de forma equivocada, a possibilidade de ocorrência de ângulo de contato maior que zero.

A autora obteve como resultado que o ângulo de contato para a área da capoeira nas duas camadas avaliadas foi elevado $\left(78,0^{\circ}\right.$, para a $0-0,10 \mathrm{~m}$, e $80,4^{\circ}$, para a 0,10 0,20 m), superior à média das demais coberturas vegetais $\left(54,8^{\circ}\right.$, para a $0-0,10 \mathrm{~m}$, e $53,5^{\circ}$, para a 0,10-0,20 m), com implicações na estimativa dos valores de $\theta_{C C}$ e $\theta_{P M P}$ os quais definem a $A D$ e o IHO. 
Os valores médios de Ds variaram de 1,11 a 1,39 $\mathrm{Mg} \mathrm{m}^{-3}$, na camada 0-0,10 m, e de 1,10 a 1,47 $\mathrm{Mg} \mathrm{m}^{-3}$, na 0,10-0,20 m (Tabela 2). Considerando-se as densidades médias obtidas para cada área e camada, foram calculados os valores das variáveis que definem o IHO e o próprio IHO, os quais constam na Tabela 3 e podem também ser obtidos a partir das linhas verticais pontilhadas na Figura 1. Na camada 0-0,10 m das áreas sob pasto e acácia, o limite inferior do IHO foi a $\theta_{\mathrm{RP}=3 \mathrm{MPa}^{\prime}}$ evidenciando-se solo compactado na média das densidades observadas. Já na camada 0,10-0,20 m, somente na capoeira o limite inferior foi a $\theta_{\text {PMP' }}$ de modo que, nas demais áreas, a densidade média observada do solo já reflete um nível de compactação cuja resistência mecânica à penetração pode estar restringindo o crescimento vegetal. Apenas para o sabiá na camada0,10-0,20 m,o IHO foi zero, pois esse foi o único caso em que a densidade média do solo (1,37 $\left.\mathrm{Mg} \mathrm{m}^{-3}\right)$ foi superior à $\operatorname{Dsc}_{\mathrm{IHO}}\left(1,31 \mathrm{Mg} \mathrm{m}^{-3}\right)$. Kaiser et al. (2009) relatam, em seu trabalho, que a densidade crítica em que o IHO tornou-se zero devido ao alto valor de $\theta_{\mathrm{RP}=3 \mathrm{MPa}}$ foi de 1,49 $\mathrm{Mg} \mathrm{m}^{-3}$. No presente estudo, a acácia, na camada 0-0,10 m, o sabiá, nas duas camadas, e o ingá, na 0,10-0,20 m, apresentaram valores de Dsc $_{\text {IHO }}$ inferiores ao citado pelos referidos autores. De acordo com a classificação proposta por Reichert, Reinert e Braida (2003), considerando a classe textural franco-argilosa, as densidades verificadas no presente estudo deveriam garantir boa qualidade física do solo sob todas as coberturas vegetais, pois os valores de densidade ficaram abaixo de 1,40 $\mathrm{Mg} \mathrm{m}^{-3}$, limite crítico para o crescimento radicular, exceção à acácia na camada 0,10-0,20 m, com 1,47 Mg m³ (Tabela 1).

Gomes, Marciano e Faustino (2018), trabalhando com os atributos físicos densidade e distribuição da porosidade na escala detalhada, relatam que, para a área da capoeira, o solo possui uma baixa densidade (Ds), alta porosidade total (PT) e elevada proporção de poros grandes, e que o pasto, apesar de apresentar distribuição de poros adequada, possui elevada Ds e baixa PT, tendo as áreas de ingá e sabiá apresentado resultados intermediários. Em relação à acácia, esta apresentou a pior qualidade física, com maior Ds, menor PT e menor proporção de poros grandes. 
Apesar de algumas áreas não terem apresentado uma distribuição adequada de poros, esse não foi o fator limitante ao desenvolvimento radicular das plantas. Os solos não perturbados por práticas de manejo proporcionam uma elevada porosidade total, formada em grande parte por macroporos, os quais não atuam diretamente no processo de retenção de água, agindo principalmente na drenagem e aeração do solo (BRADY; WEIL, 2013).

\section{CONCLUSÕES}

As camadas superficiais do solo do presente estudo, de textura franco-argilosa e com alto teor de areia, mesmo exibindo elevada compactação e degradação da estrutura, não apresentam indicadores que evidenciem problemas de aeração.

Para a faixa de densidade do solo observada no presente estudo, e considerandose a classe textural desse solo, sempre que ocorre IHO menor que a $A D$, o fator determinante é a elevada resistência mecânica do solo, evidenciando condições restritivas ao crescimento radicular, mesmo para umidades acima do ponto de murcha permanente.

O solo da capoeira, embora sem exibir restrição mecânica às raízes, apresentou valores muito baixos de IHO e de AD, o que, possivelmente, decorre da hidrofobicidade desse solo.

As densidades do solo críticas às plantas quanto a restrições mecânicas e hídricas (Dsc ${ }_{\mathrm{RP}}$ e Dsc ${ }_{\mathrm{HO}}$ ) foram mais altas sob capoeira, indicando resiliência desse solo frente ao processo de compactação.

As áreas sob leguminosas arbóreas, apresentando elevadas densidades médias e baixos valores de densidades críticas $\mathrm{DSC}_{\mathrm{RP}}$ e Dsc $\mathrm{DSO}_{\mathrm{HO}^{\prime}}$ similares às da área sob pastagem, não apresentam evidências consistentes de recuperação estrutural do solo após 17 anos da revegetação. 


\section{REFERÊNCIAS}

BENGOUGH, A. G. et al. Root elongation, water stress, and mechanical impedance: A review of limiting stresses and beneficial root tip traits. Journal of Experimental Botany, Oxford, v. 62, n. 1, p. 59-68, 2011.

BRADY, N. C.; WEIL, R. R. Elementos da natureza e propriedades dos solos. Tradução técnica Igo Fernando Lepsch. 3. ed. Porto Alegre: [s. n.], 2013.

BUSSCHER, W. J. Adjustment of flat-tipped penetrometer resistance data to a common water content. Transactions of American Society Agricultural Engineering, St. Joseph, v. 33, n. 2, p. 519-524, 1990.

COSTA, M. G. et al. Leguminosas arbóreas para recuperação de áreas degradadas com pastagem em Conceição de Macabu, Rio de Janeiro, Brasil. Scientia Forestalis, Piracicaba, v. 42, n. 101, p. 101-112, 2014.

DIAS, C. B. et al. Intervalo hídrico ótimo e densidade crítica de um Latossolo Amarelo coeso sob diferentes usos no ecossistema Tabuleiro Costeiro. Revista Ceres, Viçosa, MG, v. 63, n. 6, p. 868-878, 2016.

FRANCO, A. A. et al. Revegetação de solos degradados. Seropédica: EMBRAPA-CNPBS, 1992. 11 p. (Comunicado Técnico, 9).

GAMA-RODRIGUES, E. F. et al. Atributos químicos e microbianos de solos sob diferentes coberturas vegetais no norte do Estado do Rio de Janeiro. Revista Brasileira de Ciência do Solo, Viçosa, MG, v. 32, p. 1521-1530, 2008.

GOMES, D. S.; MARCIANO, C. R.; FAUSTINO, L. L. Physical quality of a Typic Hapludult soil under forest leguminous trees and pasture. Floresta e Ambiente, Seropédica, v. 25, n. 4, e20170400, 2018.

IMHOFF, S. et al. Quantificação de pressões críticas para o crescimento das plantas. Revista Brasileira de Ciência do Solo, Viçosa, MG, v. 25, p. 11-18, 2001.

KAISER, D. R. et al. Intervalo hídrico ótimo no perfil explorado pelas raízes de feijoeiro em um Latossolo sob diferentes níveis de compactação. Revista Brasileira de Ciência do Solo, Viçosa, MG, v. 33, n. 4, p. 845-855, 2009.

KLEIN, V. A.; LIBARDI, P. L. Densidade e distribuição do diâmetro dos poros de um latossolo vermelho, sob diferentes sistemas de uso e manejo. Revista Brasileira de Ciência do Solo, Viçosa, MG, v. 26, p. 857-867, 2002.

LEÃO, T. P. et al. Intervalo hídrico ótimo na avaliação de sistemas de pastejo contínuo e rotacionado. Revista Brasileira de Ciência do Solo, Viçosa, MG, v. 28, n. 3, p. 415-423, 2004.

LETEY, J. Relationship between soil physical properties and crop production. Advances in Soil Science, [s. I.], v. 1, p. 277-294, 1985.

LI, S. et al. Is least limiting water range a useful indicator of the impact of tillage management on maize yield? Soil \& Tillage Research, Amsterdam, v. 199, p.104602, 2020. 
LIMA, R. P. et al. Measurements and simulations of compaction effects on the least limiting water range of a no-till Oxisol. Soil Research, Austrália, v. 58, n. 1, p. 62-7, 2019.

LOPES, P. G. N. Atributos hidrodinâmicos e hidrofobicidade em um Argissolo VermelhoAmarelo sob mata atlântica secundária, pastagem degradada e leguminosas arbóreas. 2017. Dissertação (Mestrado) - Universidade Estadual do Norte Fluminense Darcy Ribeiro, Campos dos Goytacazes, 2017.

MANHÃES, C. M. C. et al. Meso-and macrofauna in the soil and litter of leguminous trees in a degraded pasture in Brazil. Agroforest System, [s. I.], v. 87, p. 993-1004, 2013.

MOREIRA, F. R. et al. Intervalo hídrico ótimo em um Latossolo Vermelho cultivado em sistema semeadura direta por 25 anos. Revista Brasileira de Ciência do Solo, Viçosa, MG, v. 38, n. 1, p. 118-127, 2014.

OLIVEIRA, I. N. et al. Least limiting water range as influenced by tillage and cover crop. Agricultural Water Management, Amsterdam, v. 225, p. 105777, 2019.

RAMALHO FILHO, A.; BEEK, K. J. Sistema de avaliação da aptidão agrícola das terras. 3. ed. rev. Rio de Janeiro: EMBRAPA; CNPS, 1995. 65 p.

REICHERT, J. M.; REINERT, D. J.; BRAIDA, J. A. Qualidade dos solos e sustentabilidade de sistemas agrícolas. Ciência e Ambiente, Santa Maria, v. 27, p. 29-48, 2003.

REICHERT, J. M.; SUZUKI, L. E. A. S.; REINERT, D. J. Compactação do solo em sistemas agropecuários e florestais: identificação, efeitos, limites críticos e mitigação. In: CERETTA, C. A.; SILVA, L. S.; REICHERT, J. M. (ed.). Tópicos Ciência do Solo. Viçosa, MG: Sociedade Brasileira de Ciência do Solo, 2007. v. 5. p. 49-134.

SANTOS, H. G. et al. Sistema brasileiro de classificação de solos. 5. ed. Brasília: EMBRAPA, 2018. 530 p.

SEKI, A. S. et al. Efeitos de práticas de descompactação do solo em área sob sistema plantio direto. Revista Ciência Agronômica, [s. I.], v. 46, n. 3, p. 460-468, jul./set. 2015.

SERAFIM, M. E. Qualidade física e intervalo hídrico ótimo em latossolo e cambissolo, cultivados com cafeeiro, sob manejo conservacionista do solo. Revista Brasileira de Ciência do Solo, Viçosa, MG, v. 37, p. 733-742, 2013.

SHARMA, P. K.; BHUSHAN, L. Physical characterization of a soil amended with organic residues in a rice-wheat cropping system using a single value soil physical index. Soil and Tillage Research, Amsterdam, v. 60, p. 143-152, 2001.

SILVA, A. P. et al. Indicadores da qualidade física do solo. In: VAN LIER, Q. J. (ed.). Física do Solo. Viçosa, MG: Sociedade Brasileira de Ciência do Solo, 2010. p. 241-281.

SILVA, A. P.; KAY, B. D.; PERFECT, E. Characterization of the least limiting water range. Soil Science Society of America Journal, Madison, v. 58, n. 6, p. 1775-1781, 1994.

SILVA, F. A. S. ASSISTAT - Assistência Estatística - versão 7.7 beta (pt). Programa computacional. Campina Grande: Universidade Federal de Campina Grande; DEAG/ CTRN, 2014. 
TAVANTTI, R. F. R. et al. Least limiting water as a soil indicator in an integrated crop-livestock systems of the Cerrado, Brazil. Geoderma Regional, Holanda, v. 19, p. e00232, 2019.

TEIXEIRA, P. C. et al. Manual de métodos de análise de solo. 3. ed. Brasília: EMBRAPA, 2017. $573 \mathrm{p}$.

TORMENA, C. A.; ARAÚJO, M. A.; FIDALSKI, J. Variação temporal do intervalo hídrico ótimo de um Latossolo Vermelho distroférrico sob sistema de plantio direto. Revista Brasileira de Ciência do Solo, Viçosa, MG, v. 31, n. 2, p. 211-219, 2007.

TORMENA, C. A.; SILVA, A. P.; LIBARDI, P. L. Caracterização do intervalo hídrico ótimo de um Latossolo Roxo sob plantio direto. Revista Brasileira de Ciência do Solo, Viçosa, MG, v. 22, n. 4, p. 573-581, 1998.

UNGER, P. W.; KASPAR, T. C. Soil compaction and root growth: a review. Agronomy Journal, Madison, v. 86, n. 5, p. 759-766, 1994.

VAN GENUCHTEN, M. T. A closed form equation for predicting hydraulic conductivity of unsaturated soils. Soil Science Society of America Journal, Madison, v. 44, n. 5, p. 892-898, 1980.

\section{Contribuição de Autoria}

\section{1 - Lucas Luís Faustino}

Agroecológo, Dr.

https://orcid.org/0000-0002-5038-4378 • lucasfaustino1987@yahoo.com.br

Contribuição: Conceituação, Curadoria de dados, Análise Formal, Investigação, Metodologia, Administração do projeto, Recursos, Software, Validação, Visualização de dados, Escrita - primeira redação, Escrita - revisão e edição

\section{2 - Cláudio Roberto Marciano}

Engenheiro Agrônomo, Dr., Professor, Pesquisador

https://orcid.org/0000-0002-5344-6087•marciano@uenf.br

Contribuição: Conceituação, Curadoria de dados, Análise Formal, Obtenção de financiamento, Investigação, Metodologia, Administração do projeto, Recursos, Software, Supervisão, Validação, Visualização de dados, Escrita - revisão e edição

\section{Como citar este artigo}

Faustino, L. L.; Marciano, C. R. Intervalo hídrico ótimo e valores críticos de densidade como indicadores de recuperação de um solo sob sistemas florestais e pasto. Ciência Florestal, Santa Maria, v. 31, n. 2, p. 658-682, 2021. DOI 10.5902/1980509833474. Disponível em: https:// doi.org/10.5902/1980509833474. Acesso em: xx mês-abreviado 2021. 